\title{
Hubungan indeks massa tubuh dengan profil lipid pada pasien diabetes melitus tipe 2
}

\author{
${ }^{1}$ Pradika H. Koampa \\ ${ }^{2}$ Karel Pandelaki \\ ${ }^{3}$ Marthen C.P Wongkar
}

\author{
${ }^{1}$ Kandidat Skripsi Fakultas Kedokteran Universitas Sam Ratulangi Manado \\ ${ }^{2}$ Bagian Ilmu Penyakit Dalam Fakultas Kedokteran Universitas Sam Ratulangi Manado \\ Email: Pradikakoampa@gmail.com
}

\begin{abstract}
Body Mass Index (BMI) is a measurement of nutritional status by calculating the ratio of height and weight. Type 2 Diabetes Mellitus (T2DM) is more common in a person with a BMI of more than normal. In patients with T2DM, there is lipid metabolism disorder, dyslipidaemia. Changes in lipid profiles consist of increased levels of total cholesterol, Low Density Lipoprotein (LDL), and triglycerides, and decreased levels of High Density Lipoprotein (HDL). This study aimed to obtain the correlation between body mass index and lipid profile in T2DM patients in Prof. Dr. R. D. Kandou Hospital Manado. This was a descriptive analytical study using patients' medical record in Endocrine Clinic Prof. Dr. R. D. Kandou Hospital Manado from September to November 2015. The Pearson correlation test showed correlations between BMI and total cholesterol levels with $r=0.037$ and $p=0.763$; between BMI and HDL levels with $r=-0.249$ and $p=0.039$; between BMI and LDL levels with $\mathrm{r}=0.091$ and $\mathrm{p}=0,455$; and between BMI and triglyceride levels with $\mathrm{r}=0.179$ and $\mathrm{p}=0.142$. Conclusion: Among T2DM patients, there were no significant correlations between body mass index and total cholesterol, LDL cholesterol, as wello as triglyceride levels. However, there was a significant correlation between body mass index and HDL levels.
\end{abstract}

Keywords: body mass index, total cholesterol, HDL, LDL, triglycerides, T2DM

\begin{abstract}
Abstrak: Indeks Massa Tubuh (IMT) merupakan salah satu pengukuran status gizi dengan menghitung perbandingan tinggi badan dan berat badan. Diabetes Melitus Tipe 2 (DMT2) lebih sering terjadi pada individu dengan IMT lebih dari normal. Pada pasien DMT2 terjadi gangguan metabolisme lipid yaitu dislipidemia. Perubahan profil lipid yang terjadi yaitu peningkatan kadar Kolesterol Total, Low Density Lipoprotein (LDL), dan trigliserida, serta penurunan kadar High Density Lipoprotein (HDL). Penelitian ini bertujuan untuk mengetahui hubungan antara IMT dengan profil lipid pada pasien DMT2di RSUP Prof. Dr. R. D. Kandou Manado. Jenis penelitian ini deskriptif analitik dengan menggunakan data rekam medik pasien di Poliklinik Endokrin Bagian/SMF Ilmu Penyakit Dalam RSUP. Prof. Dr. R. D. Kandou Manado periode September - November 2015. Hasil uji korelasi Pearson memperlihatkan nilai hubungan antara IMT dan kadar kolesterol total $r=0,037$ dan $p=0,763$; nilai hubungan antara IMT dan kadar HDL $r=-0,249$ dan $p=0,039$; nilai hubungan antara IMT dan kadar LDL $r=0,091$ dan $p=0,455$; serta nilai hubungan antara IMT dan kadar trigliserida $r=0,179$ dan $\mathrm{p}=0,142$. Simpulan: Pada pasien DMT2 tidak dijumpai hubungan bermakna antara IMT dengan kadar kolesterol total, kadar LDL, dan kadar trigliserida, namun terdapat hubungan bermakna antara IMT dengan kadar HDL.
\end{abstract}

Kata kunci: IMT, kolesterol total, HDL, LDL, trigliserida, DMT2 
Diabetes Melitus (DM) merupakan suatu kelompok penyakit metabolik yang ditandai oleh hiperglikemia akibat defek pada: kerja insulin di hati dan di jaringan perifer; sekresi insulin oleh sel beta pancreas; atau keduanya. ${ }^{1}$

International Diabetes Federation (IDF) menyebutkan bahwa prevalensi DM di dunia mencapai 1,9\% dan menjadikan DM sebagai penyebab kematian urutan ke tujuh di dunia. Pada tahun 2012 angka kejadian DM di dunia mencapai 371 juta jiwa dimana proporsi kejadian DM tipe 2 mencapai 95\% dari jumlah penderita DM di dunia. ${ }^{2}$

Berdasarkan hasil Riset Kesehatan Dasar (RISKESDAS) tahun 2013 prevalensi DM di Indonesia melalui diagnosis kerja dan gejala mencapai 2,1\%. Prevalensi DM tertinggi terdapat di provinsi Sulawesi Tengah dengan 3,7\% sedangkan Sulawesi Utara di urutan kedua dengan 3,6\%. Pada laki-laki prevalensinya 2,0\% dan perempuan 2,3\%. Dari faktor usia, prevalensi DM tertinggi pada usia 5564 tahun dengan 5,5\%. ${ }^{3}$ Jumlah pasien yang berkunjung di Poliklinik Endokrin dan Metabolik RSUP Prof. Dr. R. D. Kandou Manado periode Mei-Oktober 2011 adalah sebanyak 3.998 pasien. Dari jumlah 3.998 pasien tersebut ditemukan pasien DM tipe 2 baru sebanyak 138 pasien yang terdiri dari 60 laki-laki (43\%) dan 78 perempuan (57\%). ${ }^{4}$

Status gizi memiliki pengaruh terhadap kejadian DM tipe 2 (DMT2). IMT tinggi mempunyai resiko 2 kali lebih besar untuk terkena DMT2 dibandingkan dengan IMT rendah. Hasil penelitian menunjukkan bahwa obesitas umum berisiko 2,24 kali sedangkan obesitas abdominal berisiko 2,44 kali untuk terjadinya DM. ${ }^{5}$

Pada pasien DMT2 dapat ditemukan kelainan metabolisme lipid berupa dislipidemia. Dislipidemia adalah kelainan pada metabolisme lipid yang ditandai dengan adanya peningkatan atau penurunan fraksi lipid dalam plasma. Kelainan fraksi lipid yang utama meliputi kenaikan kolesterol total, trigliserida, Low Density Lipoprotein (LDL), dan penurunan High
Density Lipoprotein (HDL). Dislipidemia yang diakibatkan oleh DM merupakan dislipidemia sekunder. ${ }^{6}$

Status gizi yang berbeda dapat memengaruhi kadar lipid pada seseorang. Pada subjek obesitas, konsentrasi asam lemak bebas, trigliserida, kolesterol LDL lebih tinggi dibandingkan dengan orang yang tidak mengalami obesitas. Hubungan yang signifikan terdapat antara persen lemak tubuh dan berat badan pada DMT2. Prevalensi penyakit DMT2 meningkat bersamaan dengan meningkatnya IMT karena peningkatan jaringan adiposa ditandai dengan menurunnya HDL dan meningkatnya trigliserida.

\section{METODE PENELITIAN}

Jenis penelitian ini ialah deskriptif analitik dengan menggunakan data sekunder dari rekam medik RSUP. Prof. Dr. R. D. Kandou Manado. Penelitian dilakukan pada bulan Oktober 2015 Desember 2015. Populasi penelitian ini mencakup seluruh pasien DMT2 baik pria maupun wanita di Poliklinik Endokrin Penyakit Dalam RSUP. Prof. Dr. R. D. Kandou Manado. Sampel penelitian ini mencakup semua pasien DMT2 baik pria dan wanita yang berobat di Poliklinik Endokrin Penyakit Dalam RSUP Prof. Dr. R. D. Kandou Manado selama bulan September 2015 - November 2015. Variabel penelitian yaitu Indeks Massa Tubuh (IMT), kadar kolesterol total, kadar HDL, kadar LDL, dan kadar trigliserida.

\section{HASIL PENELITIAN}

Pada penelitian ini didapatkan sampel penderita DMT2 yang memenuhi kriteria inklusi berjumlah 69 pasien yang terbagi atas 35 laki-laki dan 34 perempuan.

Untuk mengetahui adanya hubungan antara IMT dengan profil lipid, digunakan analisis bivariat yaitu dengan dengan uji korelasi Pearson. Gambar 1 menunjukkan adanya hubungan positif antara IMT dengan kadar kolesterol total dengan nilai koefisien korelasi $r=0,037$ (sangat lemah) serta $\mathrm{p}=0,763$ (tidak ada hubungan yang signifikan). 
Tabel 1. Karakteristik variabel penelitian

\begin{tabular}{lcll}
\hline Variabel & L/P & Miks-Maks & Rerata \\
\hline Umur & $\mathrm{L}$ & $40-76$ & 60,08 \\
& $\mathrm{P}$ & $33-79$ & 59,03 \\
TB $(\mathrm{cm})$ & $\mathrm{L}$ & $150-176$ & 166,14 \\
& $\mathrm{P}$ & $149-169$ & 157,50 \\
$\mathrm{BB}(\mathrm{kg})$ & $\mathrm{L}$ & $55,00-86,00$ & 68,74 \\
& $\mathrm{P}$ & $42,00-85,00$ & 62,50 \\
$\mathrm{IMT}$ & $\mathrm{L}$ & $20,76-31,22$ & 24,88 \\
$\left(\mathrm{~kg} / \mathrm{m}^{2}\right)$ & $\mathrm{P}$ & $18,67-34,05$ & 25,13 \\
Kolesterol & $\mathrm{L}$ & $81-309$ & 164,74 \\
total & $\mathrm{P}$ & $105-422$ & 220,76 \\
HDL & $\mathrm{L}$ & $9-60$ & 34,26 \\
& $\mathrm{P}$ & $5-141$ & 40,29 \\
LDL & $\mathrm{L}$ & $43-231$ & 107,09 \\
& $\mathrm{P}$ & $58-333$ & 145,94 \\
Trigliserida & $\mathrm{L}$ & $39-270$ & 119,03 \\
& $\mathrm{P}$ & $64-332$ & 165,71 \\
\hline
\end{tabular}

$\mathrm{L}=$ Laki-laki

$\mathrm{P}=$ Perempuan

Tabel 2. Distribusi kadar kolesterol total berdasarkan status gizi

\begin{tabular}{lccc}
\hline \multicolumn{1}{c}{ Status Gizi } & \multicolumn{2}{c}{$\begin{array}{c}\text { Kolesterol } \\
\text { total } \\
\end{array}$} & Total \\
& Normal & Tidak & \\
\hline Normal (L) & 10 & 2 & 12 \\
Normal (P) & 4 & 7 & 11 \\
Overweight (L) & 8 & 2 & 10 \\
Overweight (P) & 6 & 2 & 8 \\
Obese I (L) & 8 & 2 & 10 \\
Obese I (P) & 6 & 6 & 12 \\
Obese II (L) & 3 & 0 & 3 \\
Obese II (P) & 1 & 2 & 3 \\
Total & 46 & 23 & 69 \\
\hline
\end{tabular}

Tabel 3. Distribusi kadar HDL berdasarkan status gizi

\begin{tabular}{lccc}
\hline \multicolumn{1}{c}{ Status Gizi } & \multicolumn{2}{c}{ HDL } & Total \\
& Normal & Tidak & \\
\hline Normal (L) & 3 & 9 & 12 \\
Normal (P) & 5 & 6 & 11 \\
Overweight (L) & 4 & 6 & 10 \\
Overweight (P) & 0 & 8 & 8 \\
Obese I (L) & 3 & 7 & 10 \\
Obese I (P) & 2 & 10 & 12 \\
Obese II (L) & 1 & 2 & 3 \\
Obese II (P) & 0 & 3 & 3 \\
Total & 18 & 51 & 69 \\
\hline
\end{tabular}

Tabel 4. Distribusi kadar LDL berdasarkan status gizi

\begin{tabular}{lccc}
\hline \multicolumn{1}{c}{ Status Gizi } & \multicolumn{2}{c}{ LDL } & Total \\
& Normal Tidak & \\
\hline Normal (L) & 7 & 5 & 12 \\
Normal (P) & 4 & 7 & 11 \\
Overweight (L) & 8 & 2 & 10 \\
Overweight (P) & 3 & 5 & 8 \\
Obese I (L) & 3 & 7 & 10 \\
Obese I (P) & 3 & 9 & 12 \\
Obese II (L) & 1 & 2 & 3 \\
Obese II (P) & 0 & 3 & 3 \\
Total & 29 & 40 & 69 \\
\hline
\end{tabular}

Tabel 5. Distribusi kadar trigliserida berdasarkan status gizi

\begin{tabular}{lccc}
\hline \multicolumn{1}{c}{ Status Gizi } & \multicolumn{2}{c}{ Trigliserida } & Total \\
& Normal & Tidak & \\
\hline Normal (L) & 8 & 4 & 12 \\
Normal (P) & 4 & 7 & 11 \\
Overweight (L) & 10 & 0 & 10 \\
Overweight (P) & 7 & 1 & 8 \\
Obese I (L) & 9 & 1 & 10 \\
Obese I (P) & 5 & 7 & 12 \\
Obese II (L) & 2 & 1 & 3 \\
Obese II (P) & 1 & 2 & 3 \\
Total & 46 & 23 & 69 \\
\hline
\end{tabular}

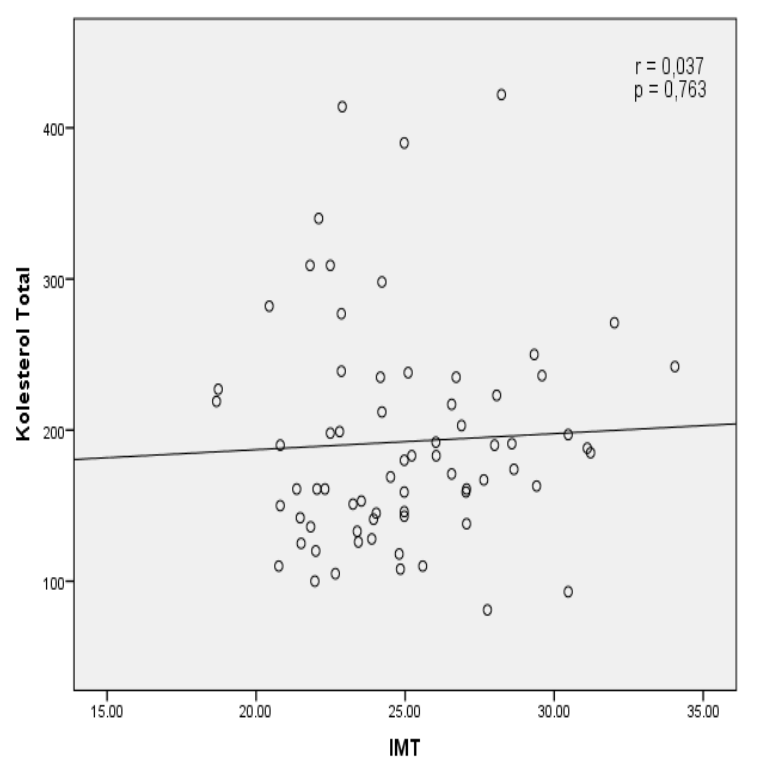

Gambar 1. Hubungan IMT dengan kadar Kolesterol total 
Koampa, Pandelaki, Wongkar: Hubungan indeks massa...

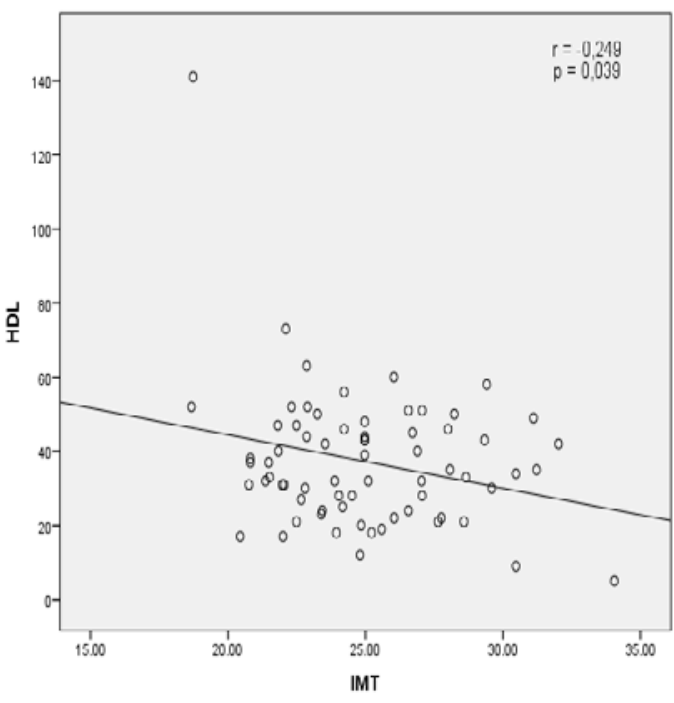

Gambar 2. Hubungan IMT dengan kadar HDL

Gambar 2 menunjukkan adanya hubungan negatif antara IMT dan kadar HDL dengan nilai koefisien korelasi $r=-0,249$ (lemah) serta $\mathrm{p}=0,039$ (ada hubungan yang signifikan).

Gambar 3 menunjukkan adanya hubungan positif antara IMT dan kadar HDL dengan nilai koefisien korelasi $\mathrm{r}=$ 0,091 (sangat lemah) serta $\mathrm{p}=0,455$ (tidak ada hubungan yang signifikan).

Gambar 4 menunjukkan adanya hubungan positif antara IMT DAN kadar trigliserida dengan nilai koefisien korelasi $\mathrm{r}$ $=0,179$ (sangat lemah) serta $\mathrm{p}=0,142$ (tidak ada hubungan yang signifikan).

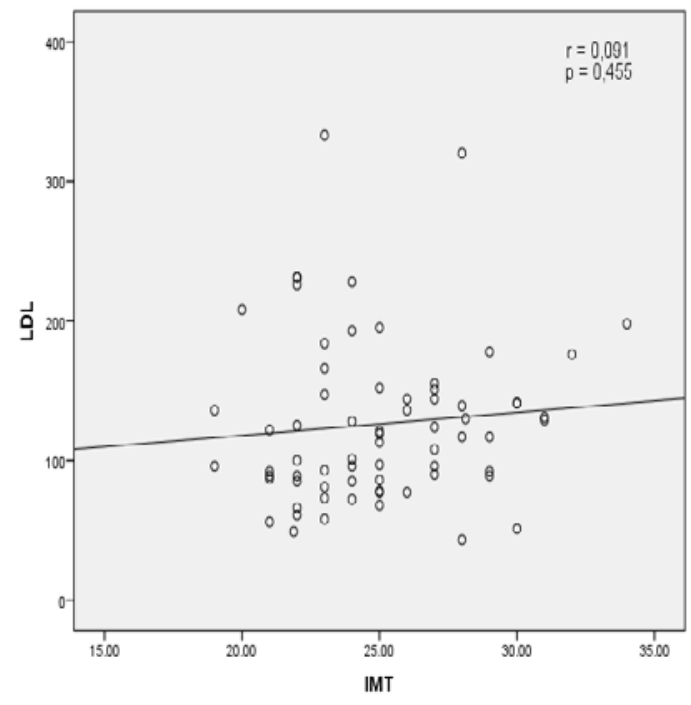

Gambar 3. Hubungan IMT dengan kadar LDL

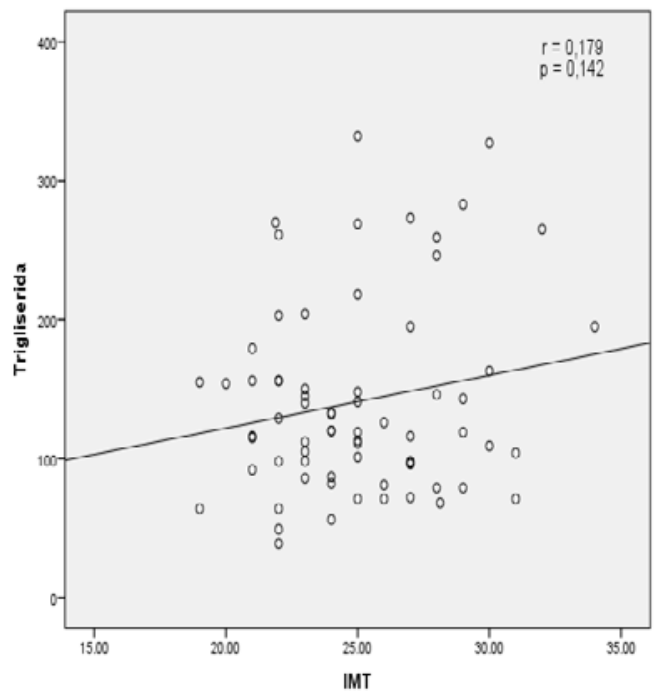

Gambar 4. Hubungan IMT dengan kadar Trigliserida

\section{BAHASAN}

Pada penelitian ini, berdasarkan jenis kelamin, jumlah sampel yang didapatkan antara laki-laki dan perempuan hampir seimbang. Frekuensi pada laki-laki berjumlah 35 dari 69 orang (50,72\%) sedangkan pada perempuan ditemukan 34 dari 69 (49,28\%). Berdasarkan kategori usia, rata-rata sampel yang didapat berusia 60,06 tahun pada laki-laki dan usia 59,03 pada perempuan. Rata-rata IMT pada lakilaki 24,88 dan 25,13 pada perempuan.

Hasil pengumpulan data diketahui bahwa $65,7 \%$ laki-laki memiliki IMT $\geq$ $23 \mathrm{~kg} / \mathrm{m}^{2}$ dan sementara $67,6 \%$ sampel perempuan memiliki IMT $\geq 23 \mathrm{~kg} / \mathrm{m}^{2}$. Hasil ini sejalan dengan hasil RISKESDAS Nasional tahun 2013, dimana perempuan memiliki prevalensi status gizi berlebih yang lebih tinggi dibanding laki-laki. ${ }^{3}$ Obesitas sering didefinisikan sebagai suatu keadaan dengan akumulasi lemak yang tidak normal atau berlebih dalam jaringan adiposa sehingga dapat mengganggu kesehatan. Peningkatan adiposa jaringan khususnya telah terbukti lebih kuat berhubungan dengan risiko penyakit metabolik meliputi DM tipe 2 dan dislipidemia., ${ }^{8,9}$

Berdasarkan kategori umur, penderita DM tipe 2 pada kelompok umur 30-40 yaitu 2 dari 69 orang (2,9\%), meningkat persentasenya menjadi $14,5 \%$ pada 
kelompok umur 41-50 tahun, dan 34,8\% pada kelompok umur 51-60 tahun. Tampak terjadi peningkatan jumlah kejadian DM tipe 2 seiring dengan peningkatan umur. Hasil penelitian ini sejalan dengan hasil RISKESDAS Nasional tahun 2013, dimana prevalensiDM berdasarkan usia yaitu usia 55-64 tahun. Penelitian di RSUP. Prof. Dr. R. D Kandou Manado pada tahun 2013 juga menemukan bahwa penderita DM tipe 2 sedikit terjadi pada usia 21-30 tahun dan terbanyak pada usia 51-60 tahun.,

Usia mempunyai hubungan dalam terjadinya sindroma metabolik. Jumlah lemak tubuh akan meningkat sesuai peningkatan umur. Menurut Garrows, prevalensi kegemukan akan terus meningkat sampai usia 50 tahun untuk pria dan umur 65 tahun untuk wanita. ${ }^{10}$

Berdasarkan hasil penelitian profil lipid didapatkan rata-rata kadar kolesterol total $164,74 \mathrm{mg} / \mathrm{dl}$ pada laki-laki dan 220,76 mg/dl pada perempuan. Rata-rata kadar HDL 34,26 mg/dl pada laki-laki dan 40,29 mg/dl pada perempuan, kadar LDL 107,09 mg/dl pada laki-laki dan 145,94 mg/dl pada perempuan, kadar trigliserida 119,03 mg/dl pada laki-laki dan 165,71 $\mathrm{mg} / \mathrm{dl}$ pada perempuan. Hal ini sejalan dengan hasil penelitian sebelumnya yang menunjukkan profil lipid pada pasien DM tipe 2 perempuan lebih tinggi dibandingkan laki-laki. ${ }^{11}$

Berdasarkan hasil penelitian diketahui 33,33\% pasien memiliki kadar kolesterol total $\geq 200 \mathrm{mg} / \mathrm{dl}$. Diketahui juga $73,91 \%$ pasien memiliki kadar HDL di bawah normal. Didapatkan 79,41\% perempuan memiliki kadar HDL $\leq 50 \mathrm{mg} / \mathrm{dl}$ dan 68,57\% laki-laki memiliki kadar HDL $\leq 40$ $\mathrm{mg} / \mathrm{dl}$. Hal sesuai dengan teori yang mengatakan bahwa gambaran dislipidemia pada DM tipe 2 yang paling sering adalah penurunan kadar HDL.Berdasarkan hasil penelitian didapatkan juga 57,97\% pasien memiliki kadar LDL $\geq 100 \mathrm{mg} / \mathrm{dl}$ dan 33,33\% pasien memiliki kadar trigliserida $\geq 150 \mathrm{mg} / \mathrm{dl}$. Hal ini tidak sesuai dengan teori yang mengatakan bahwa gambaran dislipidemia pada DMT2 yang paling sering ialah peningkatan kadar trigliserida. $^{12}$

Berdasarkan hasil uji analisis bivariat, ditemukan hubungan yang signifikan antara IMT dengan kadar HDL. Berdasarkan hasil penelitian juga ditemukan tidak ada hubungan antara IMT dengan kolesterol total, LDL serta trigliserida. Hal ini juga dapat disebabkan karena sebagian besar pasien telah menjalani pengobatan sehingga telah terjadi perubahan terhadap kadar profil lipid. Hasil ini didukung oleh hasil penelitian Chainurridha ${ }^{13}$ di Aceh juga menyatakan bahwa tidak ada hubungan yang signifikan antara IMT dengan dengan hiperkolesterolemia, peningkatan LDL, dan hipertrigliseridemia namun terdapat korelasi bermakna dengan HDL. Hasil penelitian Whidysenandri di Surabaya yang juga menyatakan bahwa tidak ada hubungan yang signifikan antara IMT dan profil lipid. ${ }^{14}$

\section{SIMPULAN}

1. Tidak terdapat hubungan yang signifikan antara Indeks Massa Tubuh dengan kadar kolesterol total.

2. Terdapat hubungan negatif yang signifikan antara Indeks Massa Tubuh dengan kadar HDL.

3. Tidak terdapat hubungan yang signifikan antara Indeks Massa Tubuh dengan kadarLDL.

4. Tidak terdapat hubungan yang signifikan antara Indeks Massa Tubuh dengan kadar trigliserida.

\section{DAFTAR PUSTAKA}

1. Rani AA, Soegondo S, Nazir AUZ, Wijaya IP, Nafrialdi, Mansjoer A. Panduan Pelayanan Medik (3rd ed). Jakarta: Interna Publishing, 2009; p. 9.

2. Fatimah NR. Diabetes Melitus Tipe 2. J Majority. 2015;4:94.

3. RISKESDAS. Jakarta: Litbangkes, 2013.

4. Awad N. Gambaran Faktor Resiko Pasien Diabetes Melitus Tipe II Di Poliklinik Endokrin Bagian/SMF FK-Unsrat RSUP Prof Dr. R. D. Kandou Manado Periode Mei - Oktober 2011. e-Biomedik. 2013;1(1):47-8.

5. Susilawati MD. Perbandingan IMT dan Indikator Obesitas Sentral terhadap 
Kejadian Diabetes Melitus Tipe 2. Buletin Penelitian Kesehatan. Maret 2015;43(1):17-22.

6. Priantono D, Sulistianingsih DP. Dislipidemia. In: Tanto C, Liwang F, Hanifati S, Pradipta EA, editors. Kapita Selekta Kedokteran (4th ed). Jakarta: Media Aesculapius, 2014; p. 783.

7. Arora M, Koley S, Gupta S, Shandu JS. A Study on Lipid Profile and Body Fat in Patients with Diabetes Mellitus. Anthropologist. 2007;9(4):295-298. [cited 22 September 2015]. Available from: www.krepublisher.com/02Journals/T-Anth-09-4-295-07-384Arora-MTt1.pdf.

8. Sugondo S. Obesitas. In: Sudoyo Aru W, Setiyohadi B, Alwi I, Simadibrata M, Setiati S, editors. Buku Ajar Ilmu Penyakit Dalam (4th ed). Jakarta: Interna Publishing, 2006; 1919-24.

9. Idapola SSJ. Hubungan Indeks Massa Tubuh dengan Keadaan Biokimiawi Darah pada Karyawan PT. Asuransi Jiwa Bumi Asih Mas Jakarta
[Skripsi]. Jakarta: FK UI; 2009.

10. Haffner S, Taegtmeyer H. Epidemic Obesity and the Metabolic Syndrome. Circulation. 2003;29:108-154.

11. Josten S, Mutmainnah, Hardjoeno. Lipid Profile in Type 2 Diabetic Mellitus Patient's. Indonesian Journal of Clinical Pathology and Medical Laboratory. 2006;13(1):20-2.

12. Krauss RM. Lipid Profile in Type 2 Diabetic Mellitus Patient's. Diabetes Care. 2004;27:1496-1504.

13. Chainurridha. Hubungan Indeks Massa Tubuh dan Lingkar Perut pada Pasien Dislipidemia di Poli Endokrin dan Metabolik RSUD Dr. Zainoel Abidin Banda Aceh Tahun 2014 [Skripsi]. Aceh: Universitas Syiah Kuala Darussalam; 2014.

14. Sitepu IW. Hubungan Indeks Massa Tubuh dengan Kadar Profil Lipid Pada Pasien Dewasa di Bagian Penyakit Dalam Rumah Sakit PHC Surabaya [Skripsi]. Surabaya: Universitas Katolik Widya Mandala; 2014. 